\title{
First-line single agent treatment with gefitinib in patients with advanced non-small-cell lung cancer
}

\author{
Yong-Mei Yin ${ }^{1 \dagger}$, Yi-Ting Geng ${ }^{1 \dagger}$, Yong-Feng Shao ${ }^{2}$, Xiao-Li Hu' ${ }^{1}$, Wei Li ${ }^{1}$, Yong-Qian Shu ${ }^{1 *}$, Zhao-Xia Wang ${ }^{3 *}$
}

\begin{abstract}
Background: Lung cancer is a malignant carcinoma which has the highest morbidity and mortality in Chinese population. Gefitinib, a tyrosine kinase (TK) inhibitor of epidermal growth factor receptor (EGFR), displays anti-tumor activity. The present data regarding first-line treatment with single agent gefitinib against non-small-cell lung cancer (NSCLC) in Chinese population are not sufficient.

Purpose: To assess the efficacy and toxicity of gefitinib in Chinese patients with advanced non-small-cell lung cancer (NSCLC), a study of single agent treatment with gefitinib in Chinese patients was conducted.

Methods: 45 patients with advanced NSCLC were treated with gefitinib (250 mg daily) until the disease progression or intolerable toxicity.

Results: Among the 45 patients, 15 patients achieved partial response (PR), 17 patients experienced stable disease (SD), and 13 patients developed progression disease (PD). None of the patients achieved complete response (CR). The tumor response rate and disease control rate was $33 \%$ and $71.1 \%$, respectively. Symptom remission rate was $72.5 \%$, and median remission time was 8 days. Median overall survival and median progression-free survival was 15.3 months and 6.0 months, respectively. The main induced toxicities by gefitinib were skin rash and diarrhea (53.3\% and $33.3 \%$, respectively). The minor induced toxicities included dehydration and pruritus of skin (26.7\% and $22.2 \%$, respectively). In addition, hepatic toxicity and oral ulceration occurred in few patients $(6.7 \%$ and $4.4 \% 2$, respectively).
\end{abstract}

Conclusions: Single agent treatment with gefitinib is effective and well tolerated in Chinese patients with advanced NSCLC.

\section{Background}

Lung cancer is a malignant carcinoma with high morbidity and mortality in Chinese population. Non-small cell lung cancer (NSCLC) accounts for approximately $80 \%$ of all lung cancers. The synthetical therapy has been developed remarkably, however the efficacy on locally advanced or metastatic NSCLC is still poor. Recently, the molecular-targeted therapy with gefitinib shows favorable performance. Gefitinib is a tyrosine

\footnotetext{
*Correspondence: shuyongqian@csco.org.cn; wangzhaox@yahoo.com.cn

+ Contributed equally

'Department of Oncology, The First Affiliated Hospital of Nanjing Medical University, Guangzhou Road. \#300, Nanjing 210029, P.R. China ${ }^{3}$ Department of Oncology, The Second Affiliated Hospital of Nanjing Medical University, Jiangjiayuan. \#121, Xiaguan District, Nanjing 210011, P.R. China Full list of author information is available at the end of the article
}

kinase (TK) inhibitor of epidermal growth factor receptor (EGFR). It blocks signal pathways involved in proliferation and survival of cancer cells [1], and displays activity against malignant tumors. Two large randomised phase II studies (IDEAL1 and 2) in patients with locally advanced or metastatic NSCLC after failure of platinum-based chemotherapy showed a higher response rate of gefitinib (12\%-18\%) [2,3]. Compared to docetaxel, gefitinib showed superior progression-free survival (PFS), objective response rate (ORR), better tolerability, and similar quality of life (QOL) improvement rates in pretreated NSCLC [4]. Gefitinib was also effective and safe in Chinese patients with recurrent advanced NSCLC [5].

\section{C) Biomed Central}


In 2006, Niho et al. reported response rate of 30\%, median survival time (MST) of 13.9 months and 1-year survival rate of $55 \%$ in advanced NSCLC after first-line single agent treatment with gefitinib[6]. Some other groups also reported that first-line single agent treatment with gefitinib may have better effect in patients with advanced NSCLC than standard first-line chemotherapy [7-10]. Gefitinib showed clinical benefits for EGFR mutation NSCLC patients with extremely poor performance status (PS) [11,12]. The large randomized trial (IPASS research) which compared gefitinib with carboplatin/paclitaxel in patients with advanced NSCLC demonstrated superiority of gefitinib relative to carboplatin/paclitaxel in terms of PFS, ORR, tolerability, and QOL improvement rates. However, the overall survival (OS) and disease-related symptom improvement rates were similar [13]. In 2009, Kim et al. demonstrated that compared to pre-gefitinib eras, the survival of advanced NSCLC patients was significantly improved in postgefitinib eras in Korea [14].

However, the present data regarding first-line treatment with single agent gefitinib against NSCLC in Chinese population are not sufficient. Here, we conducted a study of single agent treatment with gefitinib in 45 patients with advanced NSCLC in order to assess its efficacy and toxicity in Chinese patients.

\section{Materials and methods Patients}

45 patients with histologically or cytologically confirmed stage IIIB or IV NSCLC received gefitinib as first-line treatment between July 2006 and Oct 2008 at the First Affiliated Hospital of Nanjing Medical University. All of these patients were treated initially and had at least one measurable focus according to standard Response Evaluation Criteria in Solid Tumors (RECIST) [15]. These 45 patients consisted of 19 males and 26 females with median age around 61.8 years (range: $30-78$ ). 17 patients had smoking history. In terms of tumor histologic types, the patients included 26 adenocarcinomas, 4 bronchioloalveolar carcinomas, 10 squamous cell carcinomas and 5 adenosquamous carcinomas. According to American Joint Committee on Cancer (AJCC) staging manual, 14 patients were in stage IIIB and 31 patients in stage IV. The Eastern Cooperative Oncology Group Performance Status (ECOG-PS) value was less than 2 in 32 patients, and $3-4$ in 13 patients (Table 1). All patients provided written informed consent before enrollment. This protocol was approved by the Institutional Review Boards of the participating centers.

\section{Therapy}

Gefitinib (AstraZeneca Company) was administered orally $250 \mathrm{mg}$ daily, 28 days as a cycle. The treatment
Table 1 Clinical material and efficacy of the $\mathbf{4 5}$ patients

\begin{tabular}{lccccc}
\hline Characters & NO. & $\begin{array}{c}\text { CR, } \mathbf{n} \\
(\%)\end{array}$ & $\begin{array}{c}\text { PR, } \mathbf{n} \\
(\%)\end{array}$ & $\begin{array}{c}\text { SD, } \mathbf{n} \\
(\%)\end{array}$ & $\begin{array}{c}\text { PD, } \mathbf{n} \\
(\%)\end{array}$ \\
\hline $\begin{array}{l}\text { Gender } \\
\quad \text { Male }\end{array}$ & 19 & 0 & $15.8(3)$ & $36.8(7)$ & $47.4(9)$ \\
$\quad$ Female & 26 & 0 & $46.1(12)$ & $38.5(10)$ & $15.4(4)$ \\
Age(year) & & & & & \\
$\quad<70$ & 35 & 0 & $34.3(12)$ & $37.1(13)$ & $28.6(10)$ \\
$\quad$ 70 & 10 & 0 & $30.0(3)$ & $40.0(4)$ & $30.0(3)$ \\
Smoking status & & & & & \\
$\quad$ Smokers & 17 & 0 & $17.6(3)$ & $41.2(7)$ & $41.2(7)$ \\
$\quad$ Non-smokers & 28 & 0 & $42.9(12)$ & $35.7(10)$ & $21.4(6)$ \\
Tumor histology & & & & & \\
$\quad$ Adeno. & 26 & 0 & $38.5(10)$ & $42.3(11)$ & $19.2(5)$ \\
$\quad$ BAC & 4 & 0 & $75.0(3)$ & $25.0(1)$ & $0.0(0)$ \\
Squamous & 10 & 0 & $10.0(1)$ & $30.0(3)$ & $60.0(6)$ \\
$\quad$ Adenosquamous & 5 & 0 & $20.0(1)$ & $40.0(2)$ & $40.0(2)$ \\
Stage & & & & & \\
$\quad$ IIIb & 14 & 0 & $28.6(4)$ & $50.0(7)$ & $21.4(3)$ \\
$\quad$ IV & 31 & 0 & $35.4(11)$ & $32.3(10)$ & $32.3(10)$ \\
Brain metastasis & 4 & 0 & $75.0(3)$ & $25.0(1)$ & $0.0(0)$ \\
PS value & & & & & \\
$\quad \leq 2$ & 32 & 0 & $37.5(12)$ & $37.5(12)$ & $25.0(8)$ \\
$\quad$ 3 4 & 13 & 0 & $23.0(3)$ & $38.5(5)$ & $38.5(5)$ \\
\hline
\end{tabular}

was continued until disease progression or intolerable toxicity.

\section{Observation index}

We conducted a thorough physical examination on each patient to acquaint with the health status (PS method). Blood routine, hepatic and renal function, electrocardiogram, PET/CT or CT were examined. These indexes were reexamined regularly during the trial, and the image examination was performed after the first one cycle. After that, the image examination was conducted once two cycles. The follow-up of patients by telephone or outpatient service for 1 year was performed.

\section{Evaluative standards}

Tumor response was assessed as complete response $(\mathrm{CR})$, partial response (PR), stable disease (SD), or progression disease (PD) in accordance with the standard of RECIST [15]. A CR was defined as the complete disappearance of all clinically detectable tumors for at least 4 weeks. A PR was defined as an at least $30 \%$ decrease in the sum of the longest diameters of the target lesions for more than 4 weeks without new area of malignant disease. PD indicated an at least $20 \%$ increase in the sum of the longest diameter of the target lesions or a new malignant lesion. Stable disease was defined as insufficient shrinkage to qualify for PR and insufficient increase to qualify for PD. An objective response rate 
(ORR) indicated the proportion of patients achieved CR and PR, while a disease control rate (DCR) indicated the proportion of patients achieved CR, PR and SD. Progression-free survival (PFS) was measured from Day 1 of treatment until the first objective or clinical sign of disease progression. Overall survival (OS) was measured from Day 1 of treatment until the date of death. The alteration of patients' symptoms including appetite, fatigue, cough, dyspnea, hemoptysis and pain referencing to Lung Cancer Symptom Scale (LCSS) [16] was observed. Symptomatic remission was considered if the score over 25 points. Symptom remission time means the span from initial administration to symptom remission. Adverse effects including 5 degrees (0-IV) were evaluated following the standard enacted by the World Health Organization in 1981.

\section{Statistical considerations}

The data was analyzed by SPSS11.5. Intergroup comparison was conducted by X2 checking. Survival analyses were performed by Kaplan-Meier method. Survival deviation was calculated by Log-Rank test. All P-values were considered significant if $\mathrm{P} \leq 0.05$.

\section{Results}

\section{Clinical efficacy}

All of these patients were eligible. None of the patients achieved CR. 15 patients (33.3\%) achieved PR and 17 patients $(37.8 \%)$ had stable disease (SD). 13 patients (28.9\%) developed progressive disease (PD). ORR and DCR was $33.3 \%$ and $71.1 \%$ respectively. Subset analysis according to basic traits of the patients was shown in

Table 2 Gradational analysis of ORR and DCR

\begin{tabular}{|c|c|c|c|c|}
\hline Characters & ORR(\%) & $P$ value & $\mathrm{DCR}(\%)$ & $P$ value \\
\hline \multicolumn{5}{|l|}{ Gender } \\
\hline Male & 13.3 & 0.033 & 52.6 & 0.019 \\
\hline Female & 40.0 & & 84.6 & \\
\hline \multicolumn{5}{|l|}{ Age(year) } \\
\hline$<70$ & 34.3 & 1.000 & 71.4 & 1.000 \\
\hline$\geq 70$ & 30.0 & & 70.0 & \\
\hline \multicolumn{5}{|l|}{ Smoking status } \\
\hline Smokers & 17.6 & 0.082 & 58.8 & 0.281 \\
\hline Nonsmokers & 42.9 & & 78.6 & \\
\hline \multicolumn{5}{|l|}{ Tumor histology } \\
\hline Adeno. And BAC & 43.3 & 0.044 & 83.3 & 0.027 \\
\hline Non-adeno. & 13.3 & & 46.7 & \\
\hline \multicolumn{5}{|l|}{ Stage } \\
\hline Illb & 28.6 & 0.909 & 78.6 & 0.699 \\
\hline IV & 35.5 & & 67.7 & \\
\hline \multicolumn{5}{|l|}{ PS value } \\
\hline$\leq 2$ & 37.5 & 0.561 & 75.5 & 0.589 \\
\hline $3 \sim 4$ & 23.1 & & 61.5 & \\
\hline
\end{tabular}

Table 1. Table 2 showed that the efficacy of gefitinib therapy correlated with gender, tumor histology $(\mathrm{P}<$ 0.05). However, other factors such as age, smoking status, disease stage, and ECOG-PS didn't correlate with the efficacy of gefitinib therapy.

It is notable that there were 4 patients with brain metastasis in this trial, including 3 cases of PR and 1 case of SD. Brain metastatic focuses disappeared in 2 patients of $\mathrm{PR}$, and their primary tumor reduced. One of them expressed headache palliative at the day 1 . The primary and metastatic tumors of one patient reduced two weeks later.

\section{Remission of symptoms}

In this trial, except 5 patients whose PS $=0,29$ of the other 40 patients $(72.5 \%)$ achieved palliative symptoms such as fatigue, cough, pain, etc. Remission time arranged from 1 to 14 days, median remission time was 8 days.

\section{Overall survival}

MST of the 45 patients was 15.3 months by Oct 15, 2008, (95\% CI 11.22-19.38). OS arrange from 7.4 to 23 months, and the patient who had the longest OS was still alive at the most recent follow-up. The 1-year survival rate was $50 \%$. The Kaplan-Meier survival curve was showed in Figure 1. The MST of patients with adenocarcinoma and non-adenocarcinoma was 17.1 months (95\% CI 14.79-19.41) and 11.2 months (95\%CI 8.67-13.73), respectively. The MST of patients with adenocarcinoma was remarkably longer than that of non-adenocarcinoma $(\mathrm{P}=0.0149)$ (Figure 2). Other factors such as gender, smoking status, etc., had no obvious effects on survival (Smokers indicated current or former smokers, and nonsmokers was defined as persons who had never smoked.).

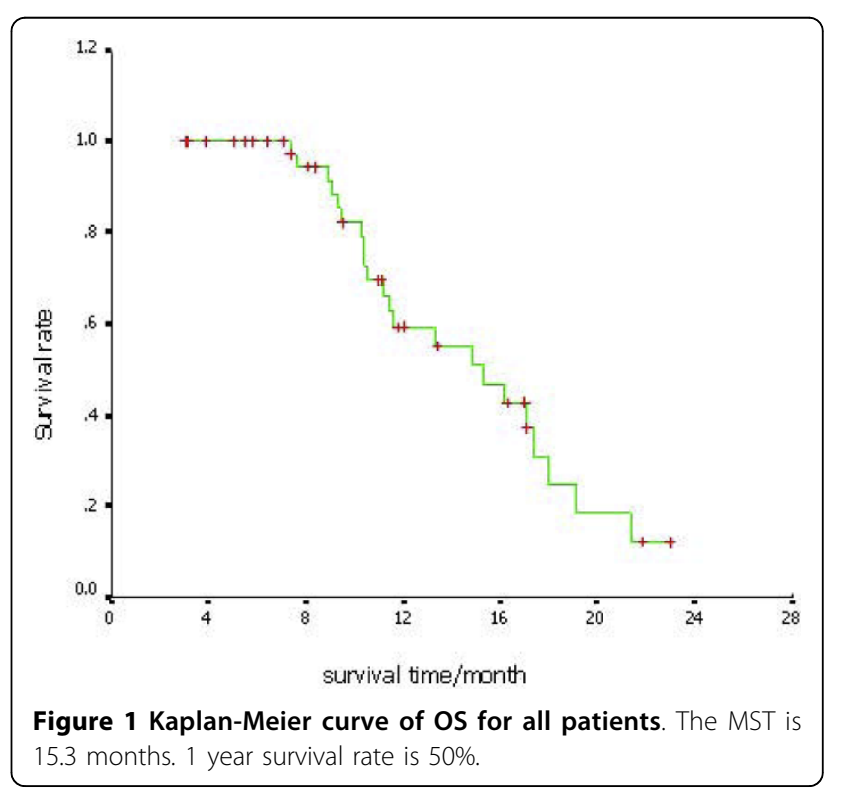




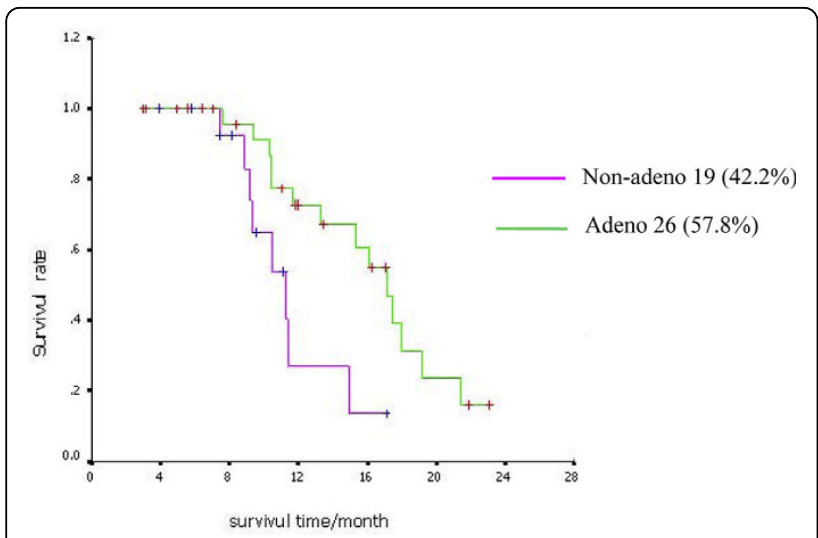

Figure 2 Kaplan-Meier curve of OS for adenocarcinoma patients (green) and non-adenocarcinoma (pink).

Adenocarcinoma was remarkably longer than that of nonadenocarcinoma $(P=0.0149)$.

\section{Progression-free survival time}

The median PFS was 6.0 months, (95\% CI 4.36-7.64). Kaplan-Meier curve of PFS was showed in Figure 3.

\section{Toxicity and adverse effects}

As shown in Table 3, the most common toxicities of gefitinib treatment were rash (53.3\%) and diarrhea (33\%). In addition, $26.7 \%$ and $22.2 \%$ of the patients showed dehydration and pruritus of skin. $6.7 \%$ of the patients showed Grade 2 or 3 hepatic toxicity. $4.4 \%$ of the patients (2 persons) showed oral ulcer. No patients developed interstitial lung disease (ILD). Most of the toxicity was grade 1 to 2, and remitted after treatment. Grade 3 rash of one patient was remitted by reducing the dose of gefitinib. The relationship between rash and OS is showed in Figure 4.

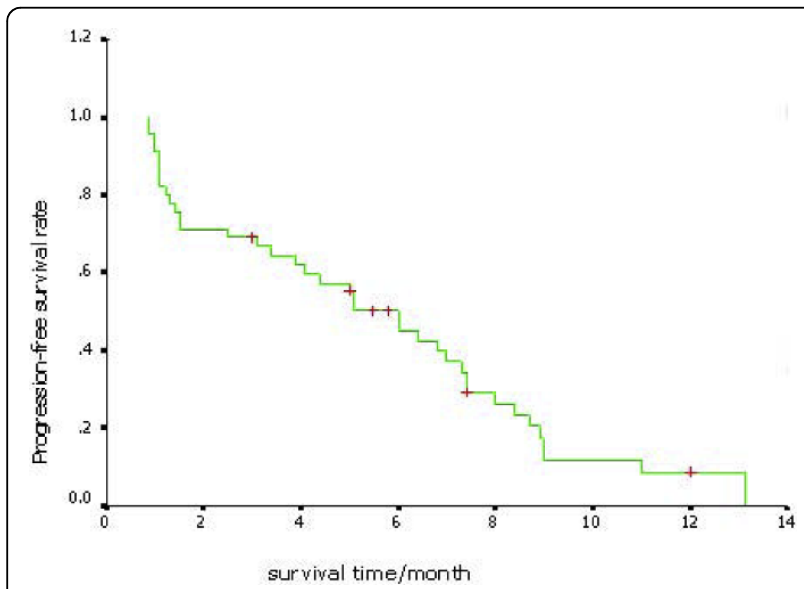

Figure 3 Kaplan-Meier curve of PFS. The median PFS was 6.0 months.
Table 3 Assessment of toxicity (case, \%)

\begin{tabular}{lccccc}
\hline Toxicity & $\mathbf{0}$ & $\mathbf{I}$ & $\mathbf{~ I I}$ & III & IV \\
\hline Rash & $21(46.7)$ & $19(42.2)$ & $4(8.9)$ & $1(2.2)$ & $0(0)$ \\
Pruritus & $35(77.8)$ & $10(22.2)$ & 0 & 0 & 0 \\
Dry skin & $33(73.3)$ & $11(24.4)$ & $1(2.2)$ & 0 & 0 \\
Diarrhea & $30(66.7)$ & $13(28.9)$ & $2(4.4)$ & 0 & 0 \\
Oral ulcer & $43(95.6)$ & $2(4.4)$ & 0 & 0 & 0 \\
Nausea/vomit & $37(82.2)$ & $8(17.8)$ & 0 & 0 & 0 \\
Hepatic toxicity & $42(93.3)$ & $1(2.2)$ & $2(4.4)$ & 0 & 0 \\
Interstitial lung Disease(ILD) & $45(100.0)$ & 0 & 0 & 0 & 0 \\
\hline
\end{tabular}

\section{Discussion}

Because of high morbidity and mortality, investigators pay more attentions to the therapy of lung cancer in recent years. Platinum-based combination chemotherapy has been the standard first-line therapy for advanced NSCLC. However, it brings about severe adverse effects such as vomiting, renal toxicity, cytopenia, etc.. Recently, molecular-targeted agents have been introduced in the treatment of NSCLC. Gefitinib, a tyrosine kinase inhibitor of EGFR, has been allowed to treat NSCLC clinically. The second-line treatment with gefitinib has response rate, survival benefit and safety not inferior to chemotherapy. Two trials in patients who previously failed platinum-based chemotherapy, IDEAL-1 and 2, revealed a favorable ORR (12-18\%), a DCR of $50 \%$, and good tolerability of gefitinib treatment $[2,3]$. Gefitinib have been suggested to have better efficacy in patients of females or non-smokers, patients with adenocarcinoma (particularly with bronchioloalveolar carcinoma), patients with previous immune/endocrine therapy, and patients with a PS of 0 or 1[2]. A trial about the treatment of NSCLC patients from Asia with gefitinib resulted in an ORR more than $25 \%$ and a DCR more than 60\% [17]. Recently, Lee et al. [5] demonstrated that, as second-line therapy, gefitinib has superior PFS, better tolerability,

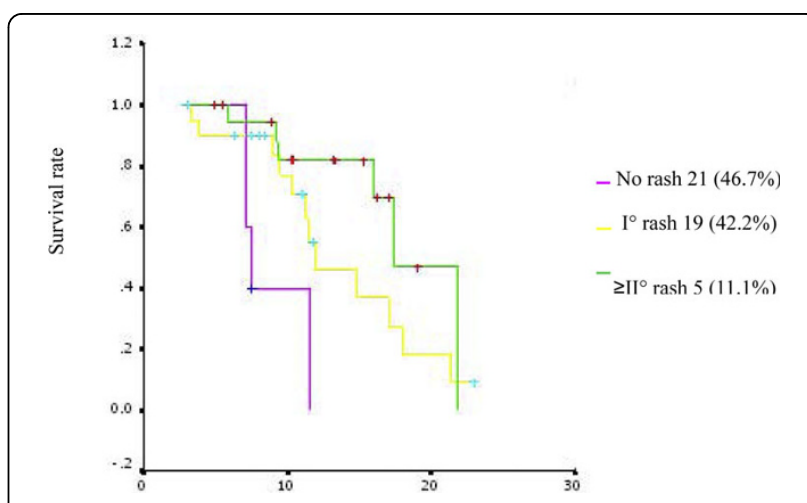

Figure 4 Kaplan-Meier survival curve of patients with grade 0 to 3 acne-like rash. 
and similar QOL improvement rates compared to docetaxel.

Nowadays, more and more clinical investigations have been carried out to evaluate the efficacy of gefitinib as first-line treatment of advanced NSCLC. Niho et al.[6] reported a response rate of $27 \%$ with gefitinib treatment in 40 patients with advanced NSCLC. Yang et al.[18] from Taiwan reported that first-line treatment with gefitinib in 196 patients with NSCLC achieved an ORR of $42 \%$, a DCR of $61 \%$, and a 1 -year survival rate of $47.5 \%$. A large phase III trial IPASS, which was designed to compare gefitinib as first-line treatment of NSCLC patients with standard chemotherapy, demonstrated superiority of gefitinib in terms of 12-month rates of PFS $(24.9 \%$ vs. $6.7 \%, \mathrm{P}<0.05)$, ORR $(43.0 \%$ vs. $32.2 \%$, $\mathrm{P}=0.0001)$, and tolerability profile compared with carboplatin plus paclitaxel. Recently, Maemondo et al.[9] reported that the gefitinib group had a significantly longer median PFS (10.8 months vs. 5.4 months; $\mathrm{P}<0.001)$, as well as a higher response rate $(73.7 \%$ vs. $30.7 \%, \mathrm{P}<0.001)$ than the standard chemotherapy group. A study conducted in Japan also showed a longer PFS in gefitinib group than the cisplatin plus docetaxel group $(9.2$ months vs. 6.3 months, $\mathrm{P}<0.0001)$ [10]. In our study of first-line treatment with gefitinib in Chinese patients with advanced NSCLC, we obtained an ORR of $33.3 \%$, a DCR of $71.1 \%$, a median PFS of 6.0 months, and a median OS of 15.3 months. These results were compatible with the reports aforementioned.

The IPASS study suggested that gefitinib would be efficacious in first-line treatment of locally advanced or metastatic NSCLC patients with adenocarcinoma who have never or seldom smoked [13]. Consistent with this result, we found that females and patients with adenocarcinoma (including bronchioloalveolar caicinoma) were more sensitive to gefitinib. Although the response rate of gefitinib in non-smokers seemed higher than that in smokers, the result had no statistical significance due to the small sample size. The OS of patients with adenocarcinoma was longer than that of patients with non-adenocarcinoma (17.1 months vs. 11.2 months, $\mathrm{P}=0.0149$ ). However, other factors such as gender and smoking status have no obvious correlation to OS. In addition, we found that the OS of patients with rash was longer than that of patients without rash, and a longer OS was coupled with greater rash. Because there were few cases with grade 2 or more serious rash, this result needs to be verified further. Moreover, our study showed favorable efficacy of gefitinib in patients with brain metastasis.

Gefitinib is well tolerated in advanced NSCLC. The common adverse effects of gefitinib were skin rash, diarrhea, anorexia, elevated aminotransferase lever, and interstitial lung disease, etc [9-11,19]. Similarly, mild toxicities including skin rash (53.3\%), diarrhea (33\%), Grade 2 or 3 hepatic toxicity (6.7\%), and oral ulcer (4.4\%) were observed in our study. No patients developed ILD. Since the tolerance of gefitinib in NSCLC is better than chemotherapy, and gefitinib could provide clinical benefits for patients with extremely poor PS $[11,12]$, it may be a better choice to treat patients who can't tolerate chemotherapy compared to best supportive care (BSC).

It has been recently reported that the sensitivity and survival benefit of gefitinib treatment was higher in NSCLC patients with EGFR mutations than the patients without EGFR mutations [20-22]. Chinese patients of lung cancer have a higher frequency of EGFR mutations than American patients. As a result, Chinese patients were much more sensitive to gefitinib than Americans [23]. Besides mutations, gene copy number and polymorphism of EGFR were also related to the responsiveness of gefitinib in advanced NSCLC [24,25]. EGFR mutations of NSCLC patients can be detected using plasma and pleural effusion samples, which provides a noinvasive method to predict the efficacy of gefitinib in advanced NSCLC [26]. Detecting the mutations of EGFR plays an important role in guiding the first-line treatment with gefitinib in patients with advanced NSCLC. Besides EGFR mutations, the favorable PFS after gefitinib treatment was also associated with high levels of serum surfactant protein D (SP-D) [27]. In future studies, we will investigate the molecules which affect and (or) can be used to predict the efficacy of gefitinib in NSCLC.

\section{Conclusions}

Single agent treatment with gefitinib is effective in patients with advanced NSCLC, and well tolerated in Chinese patients. Gefitinib could be used as firstline treatment for specific subgroups of NSCLC such as females, non-smokers, and patients with adenocarcinoma.

\section{Abbreviations}

NSCLC: non-small-cell lung cancer; TK: tyrosine kinase; EGFR: epidermal growth factor receptor; CR: complete response; PR: partial response; SD: stable disease; PD: progression disease; PFS: progression-free survival; ORR: objective response rate; QOL: quality of life; PS: performance status; ECOGPS: Eastern Cooperative Oncology Group performance status; DCR: disease control rate; OS: overall survival; RECIST: Response Evaluation Criteria In Solid Tumors; LCSS: Lung Cancer Symptom Scale; MST: median survival time; ILD: interstitial lung disease; BSC: best supportive care; TTP: time to progression; SP-D: serum surfactant protein D.

\section{Acknowledgements}

This work was supported by grants from the Jiangsu Provincial Natural Science Foundation (NO. BK2008477), the Scientific Research Foundation for the Returned Overseas Chinese Scholars, State Education Ministry 2009 (IA09), and the open project program of the Health Bureau of Jiangsu province (XK18 200904). 


\begin{abstract}
Author details
'Department of Oncology, The First Affiliated Hospital of Nanjing Medical University, Guangzhou Road. \#300, Nanjing 210029, P.R. China. 'Department of Chest Surgery, The First Affiliated Hospital of Nanjing Medical University, Guangzhou Road. \#300, Nanjing 210029, P.R. China. ${ }^{3}$ Department of Oncology, The Second Affiliated Hospital of Nanjing Medical University, Jiangjiayuan. \#121, Xiaguan District, Nanjing 210011, P.R. China.
\end{abstract}

\section{Authors' contributions}

YQS contributed to conception and design, and gave final approval of the version to be published. ZXW contributed to conception and design. YMY acquired the data and revised the manuscript critically for important intellectual content. YTG acquired the data and drafted the manuscript. YFS acquired the data. XLH and WL contributed to statistic analysis. All authors have read and approved the final manuscript.

\section{Competing interests}

The authors declare that they have no competing interests.

Received: 21 May 2010 Accepted: 15 September 2010 Published: 15 September 2010

\section{References}

1. Wakeling AE, Barker AJ, Davies DH, Brown DS, Green LR, Cartlidge SA, Woodburn JR: Specific inhibition of epidermal growth factor receptor tyrosine kinase by 4-anilinoquinazolines. Breast Cancer Res Treat 1996, 38:67-73.

2. Fukuoka M, Yano S, Giaccone G, Tamura T, Nakagawa K, Douillard JY, Nishiwaki Y, Vansteenkiste J, Kudoh S, Rischin D, Eek R, Horai T, Noda K, Takata I, Smit E, Averbuch S, Macleod A, Feyereislova A, Dong RP, Baselga J: Multi-institutional randomized phase II trial of Gefitinib for previously treated patients with advanced non-small cell lung cancer. J Clin Oncol 2003, 21:2237-2246.

3. Kris MG, Natale RB, Herbst RS, Lynch TJ Jr, Prager D, Belani CP, Schiller JH, Kelly K, Spiridonidis H, Sandler A, Albain KS, Cella D, Wolf MK, Averbuch SD, Ochs JJ, Kay AC: Efficacy of gefitinib, an inhibitor of the epidermal growth factor receptor tyrosine kinase, in symptomatic patients with non-small cell lung cancer: a randomized trial. JAMA 2003, 290:2149-2158.

4. Lee DH, Park K, Kim JH, Lee JS, Shin SW, Kang JH, Ahn MJ, Ahn JS, Suh C, Kim SW: Randomized Phase III trial of gefitinib versus docetaxel in nonsmall cell lung cancer patients who have previously received platinumbased chemotherapy. Clin Cancer Res 2010, 16:1307-1314.

5. Huang $H$, Zhang $Y$, Zhao HY, Wang ZQ, Xu F, Xu GC, Zhang L, Guan ZZ: Analysis of the efficacy and safety of gefitinib in the treatment of recurrent advanced non-small cell lung cancer in an expanded access program (EAP). Zhonghua Zhong Liu Za Zhi 2009, 31:148-151.

6. Niho S, Kubota K, Goto K, Yoh K, Ohmatsu H, Kakinuma R, Saijo N, Nishiwaki Y: First-Line Single Agent Treatment With Gefitinib in Patients With Advanced Non-Small-Cell Lung Cancer: A Phase II Study. J Clin Oncol 2006, 24:64-69.

7. D'Addario G, Rauch D, Stupp R, Pless M, Stahel R, Mach N, Jost L, Widmer L, Tapia C, Bihl M, Mayer M, Ribi K, Lerch S, Bubendorf L, Betticher DC: Multicenter phase II trial of gefitinib first-line therapy followed by chemotherapy in advanced non-small-cell lung cancer (NSCLC): SAKK protocol 19/03. Ann Oncol 2008, 19:739-745.

8. Ebi N, Semba H, Tokunaga SJ, Takayama K, Wataya H, Kuraki T, Yamamoto H, Akamine SJl, Okamoto I, Nakanishi Y: A phase II trial of gefitinib monotherapy in chemotherapy-naïve patients of 75 years or older with advanced non-small cell lung cancer. J Thorac Oncol 2008, 3:1166-1171.

9. Maemondo M, Inoue A, Kobayashi K, Sugawara S, Oizumi S, Isobe $H_{\text {, }}$ Gemma A, Harada M, Yoshizawa H, Kinoshita I, Fujita Y, Okinaga S, Hirano H, Yoshimori K, Harada T, Ogura T, Ando M, Miyazawa H, Tanaka T, Saijo Y, Hagiwara K, Morita S, Nukiwa T, North-East Japan Study Group: Gefitinib or chemotherapy for non-small-cell lung cancer with mutated EGFR. N Engl J Med 2010, 362:2380-2388.

10. Mitsudomi T, Morita S, Yatabe Y, Negoro S, Okamoto I, Tsurutani J, Seto T, Satouchi M, Tada H, Hirashima T, Asami K, Katakami N, Takada M, Yoshioka H, Shibata K, Kudoh S, Shimizu E, Saito H, Toyooka S, Nakagawa K, Fukuoka M: Gefitinib versus cisplatin plus docetaxel in patients with nonsmall-cell lung cancer harbouring mutations of the epidermal growth factor receptor (WJTOG3405): an open label, randomised phase 3 trial. Lancet Oncol 2010, 11:412-413.

11. Lee YJ, Kim HT, Han JY, Yun T, Lee GK, Kim HY, Sung JH, Lee JS: First-line gefitinib treatment for patients with advanced non-small cell lung cancer with poor performance status. J Thorac Oncol 2010, 5:361-368.

12. Inoue A, Kobayashi K, Usui K, Maemondo M, Okinaga S, Mikami I, Ando M, Yamazaki K, Saijo Y, Gemma A, Miyazawa H, Tanaka T, Ikebuchi K, Nukiwa T, Morita S, Hagiwara K, North East Japan Gefitinib Study Group: First-line gefitinib for patients with advanced non-small-cell lung cancer harboring epidermal growth factor receptor mutations without indication for chemotherapy. J Clin Oncol 2009, 27:1350-1354.

13. Mok TS, Wu YL, Thongprasert S, Yang CH, Chu DT, Saijo N, Sunpaweravong $P$, Han B, Margono B, Ichinose $Y$, Nishiwaki $Y$, Ohe $Y$, Yang JJ, Chewaskulyong B, Jiang H, Duffield EL, Watkins CL, Armour AA, Fukuoka M: Gefitinib or carboplatin-paclitaxel in pulmonary adenocarcinoma. N Engl J Med 2009, 361:947-957.

14. Kim HS, Park K, Jun HJ, Yi SY, Lee J, Ahn JS, Park YH, Kim S, Lee S, Ahn MJ: Comparison of survival in advanced non-small cell lung cancer patients in the pre- and post-gefitinib eras. Oncology 2009, 76:239-246.

15. Therasse P, Arbuck SG, Eisenhauer EA, Wanders J, Kaplan RS, Rubinstein L, Verweij J, Van Glabbeke M, Van Oosterom AT, Christian MC, Gwyther SG, European Organization for Research and Treatment of Cancer, National Cancer Institute of the United States, National Cancer Institute of Canada: New guidelines to evaluate the response to treatment in solid tumors. J Natl Cancer Inst 2000, 92:205-216.

16. Hollen PJ, Gralla RJ, Kris MG, Potanovich LM: Quality of life assessment in individuals with lung cancer: testing the lung cancer symptom scale (LCSS). Eur J Cancer 1993, 29A(Suppl 1):S51-58.

17. Shun Lu, Ziming Li: Targeted therapy of lung cancer-data from Asia. China oncology 2007, 17:8-13

18. Yang $C H$, Shih JY, Chen KC, Yu CJ, Yang TY, Lin CP, Su WP, Gow CH, Hsu C, Chang GC, Yang PC: Survival outcome and predictors of gefitinib antitumor activity in East Asian chemonaive patients with advanced nonsmall cell lung cancer. Cancer 2006, 107:1873-1882.

19. Moiseenko VM, Protsenko SA, Semenov II, Moiseenko FV, Levchenko EV, Barchuk AS, Matsko DE, Ivantsov AO, levleva AG, Mitiushkina NV, Togo AV, Imianitov EN: Effectiveness of gefitinib (Iressa) as first-line therapy for inoperable non-small-cell lung cancer with mutated EGFR gene (phase II study). Vopr Onkol 2010, 56:20-23.

20. Sequist LV, Martins RG, Spigel $D$, Grunberg SM, Spira A, Jänne PA, Joshi VA, McCollum D, Evans TL, Muzikansky A, Kuhlmann GL, Han M, Goldberg JS, Settleman J, lafrate AJ, Engelman JA, Haber DA, Johnson BE, Lynch TJ: Firstline Gefitinib in Patients with Advanced Non-Small-Cell Lung Cancer Harboring Somatic EGFR Mutations. J Clin Oncol 2008, 26:2442-2449.

21. Sugio K, Uramoto H, Onitsuka T, Mizukami M, Ichiki Y, Sugaya M, Yasuda M, Takenoyama M, Oyama T, Hanagiri T, Yasumoto K: Prospective phase II study of gefitinib in non-small cell lung cancer with epidermal growth factor receptor gene mutations. Lung Cancer 2009, 64:314-318.

22. Douillard JY, Shepherd FA, Hirsh V, Mok T, Socinski MA, Gervais R, Liao ML, Bischoff H, Reck M, Sellers MV, Watkins CL, Speake G, Armour AA, Kim ES: Molecular predictors of outcome with gefitinib and docetaxel in previously treated non-small-cell lung cancer: data from the randomized phase III INTEREST trial. J Clin Oncol 2010, 28:744-752.

23. Mu XL, Li LY, Zhang XT, Wang MZ, Feng RE, Cui QC, Zhou HS, Guo BQ: Gefitinib-Sensitive Mutations of the Epidermal Growth Factor Receptor Tyrosine Kinase Domain in Chinese Patients with Non-Small Cell Lung Cancer. Clin Cancer Res 2005, 11:4289-4294.

24. Tiseo M, Rossi G, Capelletti M, Sartori G, Spiritelli E, Marchioni A, Bozzetti C, De Palma G, Lagrasta C, Campanini N, Camisa R, Boni L, Franciosi V, Rindi G, Ardizzoni A: Predictors of gefitinib outcomes in advanced non-small cell lung cancer (NSCLC): study of a comprehensive panel of molecular markers. Lung Cancer 2010, 67:355-360.

25. Ma F, Sun T, Shi Y, Yu D, Tan W, Yang M, Wu C, Chu D, Sun Y, Xu B, Lin D: Polymorphisms of EGFR predict clinical outcome in advanced non-smallcell lung cancer patients treated with Gefitinib. Lung Cancer 2009, 66:114-119.

26. Jian G, Songwen Z, Ling Z, Qinfang D, Jie Z, Liang T, Caicun Z: Prediction of epidermal growth factor receptor mutations in the plasma/pleural effusion to efficacy of gefitinib treatment in advanced non-small cell lung cancer. J Cancer Res Clin Oncol 2010, 136(9):1341-7. 
27. Yamaguchi H, Soda H, Nakamura Y, Takasu M, Tomonaga N, Nakano H, Doi S, Nakatomi K, Nagashima S, Takatani H, Fukuda M, Hayashi T,

Tsukamoto K, Kohno S: Serum levels of surfactant protein D predict the anti-tumor activity of gefitinib in patients with advanced non-small cell lung cancer. Cancer Chemother Pharmacol 2010.

doi:10.1186/1756-9966-29-126

Cite this article as: Yin et al:: First-line single agent treatment with gefitinib in patients with advanced non-small-cell lung cancer. Journal of Experimental \& Clinical Cancer Research 2010 29:126.

Submit your next manuscript to BioMed Central and take full advantage of:

- Convenient online submission

- Thorough peer review

- No space constraints or color figure charges

- Immediate publication on acceptance

- Inclusion in PubMed, CAS, Scopus and Google Scholar

- Research which is freely available for redistribution

Submit your manuscript at www.biomedcentral.com/submit
C Biomed Central 